\title{
Ub Combination Enhanced Cellular Immune Response Elicited by HSP65 DNA Vaccine against Mycobacterium tuberculosis
}

\author{
Qingmin Wang*, Chengxiang Lei, Qiuhong Liu \\ The Division of Aviation Medicine, the Naval Medical Research Institute, Shanghai, China. \\ Email: *wqqmm_888@yahoo.com \\ Received April $7^{\text {th }}, 2013$; revised May $5^{\text {th }}, 2013$; accepted May $19^{\text {th }}, 2013$ \\ Copyright (C) 2013 Qingmin Wang et al. This is an open access article distributed under the Creative Commons Attribution License, \\ which permits unrestricted use, distribution, and reproduction in any medium, provided the original work is properly cited.
}

\begin{abstract}
This study observed the immune response induced by a HSP65 DNA vaccine fused with UbGR against Mycobacterium tuberculosis. BALB/c mice were inoculated with HSP65 DNA vaccine, UbGR-fused HSP65 DNA vaccine (UbGR-HSP65) and blank vector respectively. HSP65 DNA vaccine elicited a Th-polarized immune response. The $\mathrm{Th}_{1}$-type cytokine (IFN- $\gamma$ ) and proliferative T cell responses from spleen were improved significantly in UbGR-HSP65 group, compared with those in HSP65 DNA vaccine group. Furthermore, this fusion DNA vaccine also led to an increased ratio of $\operatorname{IgG}_{2 \mathrm{a}}$ to $\mathrm{IgG}_{1}$ and the cytotoxicity of $\mathrm{T}$ cells. IFN- $\gamma$ intracellular staining of splenocytes indicated that UbGR-HSP65 fusion DNA vaccine could activate $\mathrm{CD}^{+}$and $\mathrm{CD} 8^{+} \mathrm{T}$ cells, with much higher $\mathrm{CD} 8^{+} \mathrm{T}$ cells. Thus, this study demonstrated that the UbGR fusion could improve HSP65-specific cellular immune responses, which is helpful to protect against TB infection.
\end{abstract}

Keywords: Mycobacterium tuberculosis; HSP65; Ubiquitin; Immune Response

\section{Introduction}

Infection with Mycobacterium tuberculosis remains to be a major cause of morbidity and mortality throughout the word, resulting in 3 million deaths and over 9 million new cases of tuberculosis each year [1]. WHO has estimated that in the next two decades more than a billion people will be newly infected and about 36 million people will die from TB if control of this disease is not substantially strengthened within two decades [2]. BCG vaccination protects children against tuberculosis meningitis, but confers a variable protection (ranging from $0 \%$ to $80 \%$ ) against pulmonary TB in adults [3]. In recent years, the emergence and spread of multidrug-resistant $\mathrm{TB}$ (MDR-TB) and extensively drug-resistant TB (XDR-TB) and coinfection with TB/HIV pose serious challenges to effective TB control [4]. Increased emergency of multidrug-resistant (MDR) strain of M.TB and co-infection with HIV have complicated the situation. Therefore, new and improved TB vaccines are urgently needed to control TB effectively. A number of strategies have been proposed for improving the efficacy of vaccines against TB including inactivated vaccines, subunit vaccines and

${ }^{*}$ Corresponding author.
DNA vaccines [5-9].

To develop new vaccines requires full understanding of the protection mechanism against TB. As M. tuberculosis is an intracellular pathogen, the crucial factor of protective immunity against TB is a T-cell mediated response characterized by the secretion of IFN $-\gamma$ and other cytokines [10]. Hence, the new vaccines which are able to provoke potent protective cellular immunity are urgently needed. DNA vaccines mimic the effects of live attenuated vaccines to induce major histocompatibility complex class-I-restricted $\mathrm{CD} 8^{1} \mathrm{~T}$ cell responses and $\mathrm{Th}_{1}$-type response, which are thought to mediate killing of intracellular pathogens. However, the efficacy of DNA vaccines is limited due to problems related to delivery, animal species and degradation of plasmid DNA, resulting in modest cellular and humoral immune responses. In the past years, DNA vaccines also have been studied against tuberculosis in animal models [11-16]. These DNA vaccines encoding Ag85A/B/C, ESAT-6, MPT64, PST1/2/3, $38 \mathrm{kDa}$ or HSP70, when used individually or in combination, have conferred inferior or similar to protection against $\mathrm{M}$. TB challenge than that of BCG. Hence, the efficacy of DNA vaccines against TB needs more improvement. To improve the efficacy of DNA vaccines, 
numerous studies have explored methods to improve immune responses by optimizing plasmid design, vaccine delivery systems and adjuvants.

Heat shock protein 65 (HSP65) of MTB is an important immune-protective antigen that can be identified specifically by $10 \%-20 \%$ of reactive T cells in MTB-infected mice, making it a promising candidate as a protective antigen. Experiment results suggest that HSP65 is not only an important component of a preventive vaccine, but also a candidate for a therapeutic vaccine. However, in experimental mouse models, DNA vaccines encoding HSP65 induced partial protection against experimental tuberculosis and the efficacy of HSP65 DNA vaccines varied with the method of DNA introduction $[17,18]$. So, it is needed to improve the efficacy of HSP65 DNA vaccine by some measures. As it is known, Ub-proteasome system plays a key role in antigen presentation through MHC class I pathway [19]. So, ubiquitin was reported to enhance DNA vaccine responses against antigens in the adjuvant setting. When a protein is fused to $\mathrm{Ub}$, the degradation of the protein in proteasome and presentation can be enhanced, resulting in an improvement of immune response. In this study, we demonstrated that UbGRHSP65 fusion DNA vaccine was capable of improving the cellular immune response against HSP65.

\section{Materials and Methods}

\subsection{Mice}

$\mathrm{BALB} / \mathrm{c}$ female mice, 6 - 8 weeks old, were bred in the animal facilities of the Second Military Medical University (SMMU). All procedures performed on animals were conducted according to the guidelines for the care and use of laboratory animals of SMMU under protocols approved by the institutional Animal Care and Use committee at the SMMU.

\subsection{Cell Transfection}

The recombinant plasmid pcDNA3-HSP65 was transfected into P815 (H-2 ${ }^{\mathrm{d}}$ a lymphoma cell line, from Type Culture Collection of Chinese Academy of Sciences) cells by liposome (Roche Molecular Biochemicals) according to the manufacture's instruction. After selection in medium supplemented with G418 $(800 \mu \mathrm{g} / \mathrm{ml})$, stable transfectants were subcloned by limiting dilution and then determined by RT-PCR and immunochemistry methods.

\subsection{Immunocytochemistry}

The expression of HSP65 protein was detected by immunocytochemistry. P815 stable transfectants were fixed in $4 \%$ paraformaldehyde for $10 \mathrm{~min}$ and placed on a poly-1-lysine-treated microslide. And were then air-dri- ed for $30 \mathrm{~min}$. Slides were redehydrated and blocked using $1 \%$ BSA in PBS plus $0.1 \%$ Triton $\mathrm{X}-100(\mathrm{pH} 7.2)$ for $1 \mathrm{~h}$. Then slides were incubated overnight at $4^{\circ} \mathrm{C}$ in a humid chamber with appropriate sera diluted at 1:20 in PBS from the patients infected with M. tuberculosis (provided by Dr. Xiao An with the permission of patients). After washing in PBS (three times for $10 \mathrm{~min}$ ), the bound human immunoglobulin was detected by incubation for $24 \mathrm{~h}$ at $4^{\circ} \mathrm{C}$ with goat anti-human-HRP-conjugated second antibody (Southern Biotechnology Associates, SBA) diluted 1:100 in PBS plus $1 \%$ goat serum. After washed in PBS (three times for $10 \mathrm{~min}$ ), the interest antigen was colored by DAB substrate and the slides were counterstained with hematoxylin.

\subsection{Plasmid Construction and Preparation}

The cDNA of HSP65 is cloned from the genome of cultured Mycobacterium tuberculosis by PCR method. The primers are as following: forward primer 5 'gcgc aagctt gccacc atg gcc aag aca att gcg tac gac gaa gag 3', reverse primer 5' gc tctaga tca gaa atc cat gcc acc cat gcc acc cat gtc gc 3'. The PCR condition is as following: 35 cycles $\left(94^{\circ} \mathrm{C} 1 \mathrm{~min}, 65^{\circ} \mathrm{C} 1 \mathrm{~min}, 72^{\circ} \mathrm{C} 1 \mathrm{~min}\right), 72^{\circ} \mathrm{C} 10 \mathrm{~min}$. Then the cDNA of HSP65 was inserting into the Hind $I I I$ and $X b a$ I EcoR I restriction sites of pcDNA3 plasmid (Invitrogen), downstream of the CMV early promoter. For the construction of ubiquitin-HSP65 fusion DNA vaccine, the cDNA encoding the ubiquitin with Hind III and Nhe I restriction sites was obtained from mouse testicle by RT-PCR. An arginine (R) was added to the C-terminal residues of Ub. The cDNA of HSP65 antigen with NheI and EcoRI restriction sites was also obtained by PCR, not including the starting condon. The spacer sequence (GGGGS) was added between the ubiquitin and HSP65 antigen. Plasmids used in this study were prepared with alkaline lysis method followed by TritonX114 treatment to remove endotoxin [20].

\subsection{Vaccination Protocol}

For DNA vaccination, mice were injected with pcDNA3HSP65 or pcDNA3-ub-HSP65 (UbGR-HSP65) into both quadriceps with $2 \times 50 \mu \mathrm{g}$ DNA three times at 3 weeks intervals. Mice inoculated with pcDNA3 plasmid or pcDNA3-ub was as negative controls. To enhance muscle cells uptake of plasmid DNA [20], 25\% sucrose was injected into the muscles of both quadriceps $15 \mathrm{~min}$ before plasmid inoculation.

\subsection{Enzyme-Linked Immunoabsorbent Assay (ELISA)}

Anti-HSP65 IgG, IgG $\operatorname{Ig}_{1}, \operatorname{IgG}_{2 \mathrm{a}}$ were measured by ELISA in individual serum sample from vaccinated mice. The 
method was as described previously [21], using recombinant HSP65 protein ( $1 \mu \mathrm{g}$ per well) [22] and anti-mouse $\mathrm{IgG}, \operatorname{IgG}_{1}$ or $\operatorname{IgG}_{2 \mathrm{a}}$ coupled to horseradish peroxidase (HRP) (Southern Biotechnology Associates, SBA). The antibody titers were determined according to the optical density $(O D 450 \mathrm{~nm})$. Finally, the relative ratio of $\mathrm{IgG}_{2 \mathrm{a}}$ to $\operatorname{IgG}_{1}$ was calculated.

\subsection{Lymphocytes Proliferation Assay}

Mice were sacrificed 3 weeks after the last immunization. Spleens from each group were pooled and analyzed. Th-cell proliferation assay was performed as previously described [23]. Briefly, the isolated spleen cells were resuspended to a concentration of $5 \times 10^{6}$ cells $/ \mathrm{ml}$. A volume of $100 \mu \mathrm{l}$ of cell suspension was added to 96-well plates and the HSP65 protein [22] was added to the wells in triplicate at the final concentration of $5 \mu \mathrm{g} / \mathrm{ml}$. The plates were incubated at $37^{\circ} \mathrm{C}$ in an atmosphere of $5 \%$ $\mathrm{CO}_{2}$ for $66 \mathrm{~h}$. Then the proliferation responses were detected by MTT [3-(4, 5-dimethylthiazol-2-yl) 2, 5-diphenyltetrazolium bromide] ( $5 \mathrm{mg} / \mathrm{ml}$, Sigma) method and the stimulation index (SI) was calculated. The stimulation index was determined from the formula: stimulation index $(\mathrm{SI})=$ experimental $\mathrm{OD} /$ negative $\mathrm{OD}$. To assure that cells were healthy, $10 \mu \mathrm{g} / \mathrm{ml}$ ConA was used as a polyclonal stimulator for positive control.

\subsection{Evaluation of Cytokines Production in Vitro}

Single splenocyte suspension from immunized mice was diluted in $10 \%$ bovine calf serum-supplemented RPMI 1640 to $5 \times 10^{6} \mathrm{cells} / \mathrm{ml}$. A volume of $100 \mu \mathrm{l}$ of cell suspension was added to 96-well plates (Costar) and the HSP65 protein was added to the wells in triplicate at the final concentration of $5 \mu \mathrm{g} / \mathrm{ml}$. After $72 \mathrm{~h}$ incubation, cell-free supernatants were harvested and were screened for the presence of IFN- $\gamma$ and IL-4 with an ELISA detection system (Jingmei, Biotech) according to the manufacture's instruction.

\subsection{Intracellular IFN- $\gamma$ Measurement Using Flow Cytometry}

Splenocytes from vaccinated mice were cultured at $2.5 \times$ $10^{6} / \mathrm{ml}$ in 24-well tissue culture plates (Nunclon, Roskilde, Denmark) in the presence of $5 \mu \mathrm{g}$ of HSP65 protein/ml for 3 days. Brefeldin A (Sigma, St. Louis, Mo.) was added to the cultures for the last $5 \mathrm{~h}$ to prevent secretion of the intracellular cytokine. One million cells from each group were first incubated with fluorescein isothiocyanate-conjugated anti-CD4 Ab (clone RM4 to 4 PharMingen) or $\mathrm{CD} 8 \mathrm{Ab}$ for $30 \mathrm{~min}$ at $4^{\circ} \mathrm{C}$. Cells were then washed, fixed with $4 \%$ paraformaldehyde, and permeabilized with phosphate buffered saline containing
$0.1 \%$ saponin. To label intracellular IFN- $\gamma$, cells were incubated with phycoerythrin-conjugated anti-IFN- $\gamma \mathrm{Ab}$ (clone XMG1.2; PharMingen) for 1 hour at room temperature, washed, and acquired on a cytofluorometer (FACSCALIBUR; BD, Mountain View, Calif). Lymphocytes were gated by their forward and side light scattering properties, and 100,000 cells were acquired in the lymphocyte gate. Analysis was performed by Cell Quest software.

\subsection{Cytotoxicity Assay of T Cell}

Spleen cells adjusted to a concentration of $10^{7} / \mathrm{ml}$ from in vivo-primed mice were co-cultured with mitomycin (10 $\mu \mathrm{g} / \mathrm{ml}$ ) treated target cells (P815-HSP65, $5 \times 10^{5} / \mathrm{ml}$ ) in a $10 \mathrm{ml}$ cell suspension in RPMI 1640 for 5 days at $37^{\circ} \mathrm{C}$ in $5 \% \mathrm{CO}_{2}$. Twenty units per milliliter recombinant murine IL-2 (Biosource) was also added to the cell solution for 5 days. The P815 cell was used as a negative control.

To measure the specific lysis of the target cells, we used the lactate dehydrogenase (LDH) release assay, which yields highly similar results as the standard chromium release assay, but does not require the use of radioisotopes. In 96-well round-bottom plates, effector cells were incubated with target cells at different $\mathrm{E} / \mathrm{T}$ ratio for $4 \mathrm{~h}$ in phenol red-free RPMI 1640 containing $2 \%$ BSA, $2 \mathrm{mM}$ glutamine, and $1 \%$ penicillin and streptomycin. After centrifuging the plates at $250 \times \mathrm{g}$ for 10 min, $100 \mu \mathrm{l}$ per well of the supernatant was then transferred to 96 -well plates, and lysis was determined by measuring LDH release using cytotoxicity detection kit (Roche Molecular Biochemicals). The released LDH converted the added substrate tetrazolium salt into red formazan product, and the amount of color is proportional to the number of lysed cells. The absorbance values from supernatants were recorded at $O D 492 \mathrm{~nm}$ on an ELISA microplate reader. The percent lysis was calculated as follows:

$$
\frac{(\text { sample release }- \text { spontaneous release }) \times 100 \%}{(\text { total release }- \text { spontaneous release }) \times 100 \%} \text {. }
$$

\subsection{Statistical Analysis}

The statistical significance of differential findings between experimental groups was determined by Student's test. Data were considered statistically significant at $P<$ 0.05 .

\section{Results}

\subsection{Construction of pcDNA3-HSP65 and UbGR-HSP65 Fusion DNA Vaccine}

The recombinant pcDNA3-HSP65 plasmid was con- 
firmed by Hind III and Xba I digestion. The UbGR-HSP65 fusion DNA vaccine was confirmed respectively by Hind III and Nhe, Nhe I and EcoR I, Hind III and EcoR I digestion (Figure 1). Finally, the sequences of the two DNA vaccines were shown to be correct by sequencing. After a large scale of preparation, the plasmids were suspended in endotoxin-free PBS. DNA was quantified by spectrophotometry at $260 \mathrm{~nm}$ and the final concentration of the solution was adjusted to $1 \mu \mathrm{g} / \mu \mathrm{l}$ of DNA in PBS.

\subsection{The Stable Expression of HSP65 Protein in P815 Cells}

The purpose of transfection experiment was to obtain the specific target cells for cytotoxicity assay. After selection by $\mathrm{G} 418(800 \mu \mathrm{g} / \mathrm{ml})$, fifteen clones were obtained and four clones of transfected cells were randomly chosen and screened for HSP65-mRNA by reverse transcription-PCR. After electrophoresis, a single band about 1.6 $\mathrm{kb}$ in length was observed in clone I II III IV. And then, the expression of HSP65 was further examined in clone I by immunocytochemistry. The immunostaining was restricted to the cytoplasm of the cells transfected with pcDNA3-HSP65 plasmid. However, no staining was detected in P815 cells. No staining signals were detected with the sera from control health people, which indicated that the staining is specific. Those results demonstrated that HSP65 antigen could be expressed stably in P815 cells. We chose clone I as target cells in the cytotoxicity assay.

\subsection{Production of Antibodies Induced by Different Vaccines}

To determine the level of HSP65-specific IgG elicited by

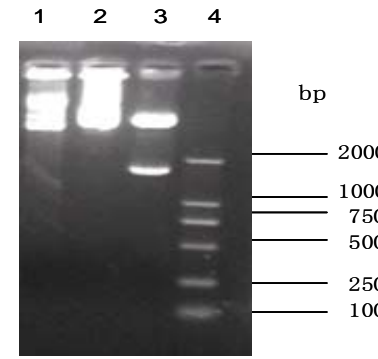

(a)

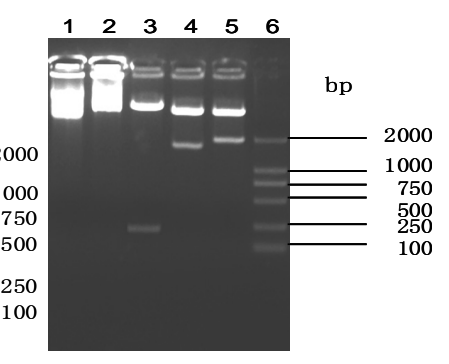

(b)
Figure 1. Analysis of (a) pcDNA3-HSP65 and (b) UbGRHSP65 fusion DNA vaccine by endonulcease digestion. (a) lane 1, pcDNA3 plasmid; lane 2, pcDNA3-HSP65 recombinant plasmid; lane 3, pcDNA3-HSP65 digested by Hind III and $X b a$ I; lane 4, DL 2000 marker. (b) lane 1, pcDNA3 plasmid; lane 2, pcDNA3-Ub-HSP65 recombinant plasmid; lane 3, pcDNA3-Ub-HSP65 digested by Hind III and Nhe I; lane 4, pcDNA3-Ub-HSP65 digested by Nhe I and EcoR I; lane 5, pcDNA3-Ub-HSP65 digested by Hind III and EcoR I. different vaccines, mice of different groups were immunized three times at 3 weeks intervals. Three weeks after the last immunization, the sera from mice were collected by retro-orbital bleeding and antigen-specific antibodies were detected by ELISA. As shown in Figure 2, compared with the pcDNA3 vector group or pcDNA3-ub group, the HSP65 DNA vaccine elicited a significantly higher level of $\operatorname{IgG}(P<0.01)$. However, the IgG level in the UbGR-HSP65 fusion DNA vaccine group was lower than that in HSP65 DNA vaccine group $(P<0.01)$.

The IgG subclasses give an indication of the $\mathrm{Th}_{1}$ versus $\mathrm{Th}_{2}$ nature of the immune response. We also detected the relative ratio of $\operatorname{IgG} 2 \mathrm{a} / \mathrm{IgG1}$. As shown in Figure 3, although the $\operatorname{IgG}$ level decreased in the Ub fusion DNA vaccine group, the relative ratio of $\mathrm{IgG} 2 \mathrm{a} / \mathrm{IgG} 1$ increased significantly in the fusion DNA vaccine $(P<0.05)$, compared with the HSP65 DNA vaccine group.

\subsection{Lymphocyte Proliferation and Cytokine Production by Splenocytes from Vaccinated Mice}

$\mathrm{T}$ helper cells play an important role in eliciting both humoral and cellular immune responses via expansion of antigen-stimulated $\mathrm{B}$ cells and expansion of $\mathrm{CD} 8^{+} \mathrm{T}$ cells.

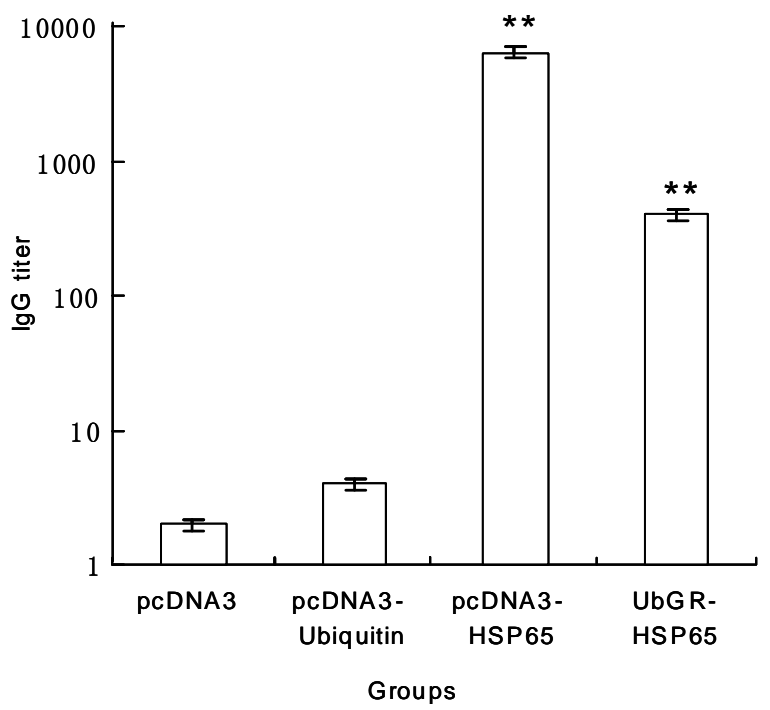

Figure 2. The HSP65-specific IgG titer in mice immunized by different DNA vaccines. Each group of mice $(n=8)$ was immunized respectively by the blank vector, pcDNA3-ubiquitin, pcDNA3-HSP65 DNA vaccine or UbGR-HSP65 DNA vaccine at 0,3 , and 6 weeks. Mice were bled at 3 weeks after the last immunization and HSP65-specific IgG titer was detected by ELISA. Optical density was measured at 450 nm. Data which are shown represented geometric mean titers (GMT) and standard errors for each group of animals. ${ }^{* *} P<0.01$ pcDNA3-HSP65 vs pcDNA3 group or pcDNA3ubiquitin group; ${ }^{* *} P<0.01$ pcDNA3-HSP65 vs UbGRHSP65 group. The experiment was repeated three times. 


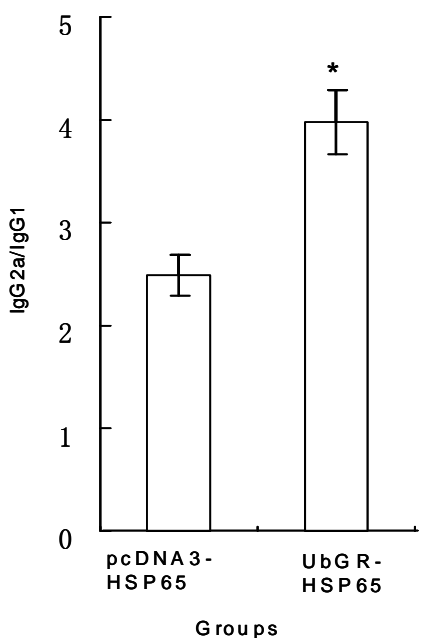

Figure 3. The ratio of $\operatorname{IgG}_{2 a}$ titer to $\operatorname{IgG}_{1}$ titer in different groups. The mice were immunized as described in Figure 1. The titers of $\operatorname{IgG}_{2 \mathrm{a}}$ and $\mathrm{IgG}_{1}$ were detected respectively. The ratio of $\operatorname{IgG}_{2 \mathrm{a}} / \mathrm{IgG}_{1}$ was obtained by dividing the titer of $\mathrm{IgG}_{2 \mathrm{a}}$ by that of $\operatorname{IgG}_{1}$. ${ }^{*} P<0.05$ UbGR-HSP65 group $v s$ pcDNA3-HSP65 group. The experiment was repeated three times.

Hence, it is important to measure proliferation of $\mathrm{T}$ cells after immunization with vaccines when stimulated in vitro with a specific antigen. In our experiment, HSP65 $(5 \mu \mathrm{g} / \mathrm{ml})$ or ConA $(10 \mu \mathrm{g} / \mathrm{ml})$ was used as a specific stimulator or a polyclonal stimulator of $\mathrm{T}$ cells respectively. As shown in Figure 4, a low background level of $\mathrm{T}$-cell proliferation was observed in vector control group and pcDNA3-ub group. A significant increase of T cells proliferation $(P<0.01)$ was observed in pcDNA3-HSP65 group compared with vector group or pcDNA3-ub group. The ubiquitinated HSP65 DNA vaccine significantly enhanced Th-cell proliferation responses compared with non-ubiquitinated HSP65 DNA vaccine $(P<0.01)$.

As a specific indicator of $\mathrm{CD}^{+} \mathrm{T}$-cell activation, the cytokines were also detected. $\mathrm{Th}_{1}$-associated cytokines (IL-2, IFN- $\gamma$ ) and $\mathrm{Th}_{2}$-associated cytokines (IL-4, IL-5 and IL-10) are major parameters in our understanding of the polarization of immune responses. $\mathrm{Th}_{1}$ immune responses are thought to drive induction of cellular immunity, whereas $\mathrm{Th}_{2}$ immune responses preferentially drive humoral immunity. In this study, the level of IFN- $\gamma$ and IL-4 was examined.

As demonstrated in Figure 5, the level of IFN- $\gamma$ was significantly higher in HSP65 DNA vaccine group than that in pcDNA3 group or in pcDNA3-ub group. The secretion of IFN- $\gamma$ significantly increased in UbGR-HSP65 fusion DNA vaccine group $(P<0.01)$ compared with HSP65 DNA vaccine group. However, the level of IL-4 was lower in fusion DNA vaccine group than that in non-fusion vaccine group $(P<0.01)$. In HSP65 DNA vaccine group, the level of IFN- $\gamma$ was higher than that of

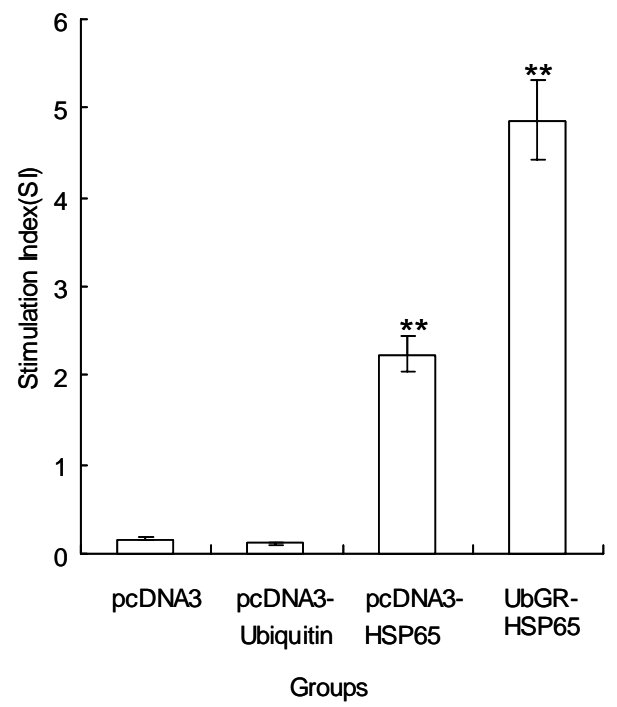

Figure 4. The proliferation of splenocytes after in vitro stimulation with HSP65 protein. Different group of mice ( $n$ $=8$ ) were respectively immunized by pcDNA3 vector, pcDNA3-ubiquitin, pcDNA3-HSP65 or UbGR-HSP65 DNA vaccines three times at 3 weeks interval. Three weeks after the last immunization, spleen cells from sacrificed mice were pooled and stimulated with $5 \mu \mathrm{g} / \mathrm{ml}$ HSP65 protein, or $10 \mu \mathrm{g} / \mathrm{ml}$ ConA as a positive control. After $66 \mathrm{~h}$ stimulation, samples were assayed in triplicate. The ConA control sample showed a stimulation index of $6.31 \pm 0.92$. Values and bars represent the mean and S.D. This experiment was repeated, with the expected results. ${ }^{* *} P<0.01$ pcDNA3-HSP65 group vs pcDNA3 group or pcDNA3-ubiquitin group; ${ }^{*} P<$ 0.01 UbGR-HSP65 group vs pcDNA3-HSP65 group. Eight spleens were pooled and the experiment was repeated three times.

IL-4, which indicated the HSP65 DNA vaccine elicited a $\mathrm{Th}_{1}$-profile immune response. The Ub fusion DNA vaccine increased the secretion of IFN $-\gamma$ and decreased the level of IL-4, which demonstrated that the Ub fusion enhanced the $\mathrm{Th}_{1}$-type immune response.

\subsection{IFN- $\gamma$ Intracellular Staining for Splenocytes in Vaccinated Mice}

Since IFN- $\gamma$ is clearly a key molecule in the anti-tuberculosis protective response. The role of $\mathrm{CD}^{+}$and $\mathrm{CD}^{+} \mathrm{T}$ cell for secreting IFN $-\gamma$ was investigated by intracellular staining. As shown in Figure 6, the frequency of IFN- $\gamma^{+}$ CD4 T cells and IFN- $\gamma^{+}$CD8T cells was higher in HSP65 DNA vaccine group than those in pcDNA3 vector group or in pcDNA3-ub group. The frequency of IFN $\gamma^{+} \mathrm{CD} 8 \mathrm{~T}$ cells was much higher in the spleen of the UbGR-HSP65 fusion DNA vaccine group than that in HSP65 DNA vaccine group $(P<0.01)$. Although to a lesser extent, the frequency of IFN- $\gamma^{+} \mathrm{CD} 4 \mathrm{~T}$ cells was also higher in the UbGR-HSP65 fusion DNA vaccine group, compared with the HSP65 DNA vaccine group $(P<0.05)$. Overall, 


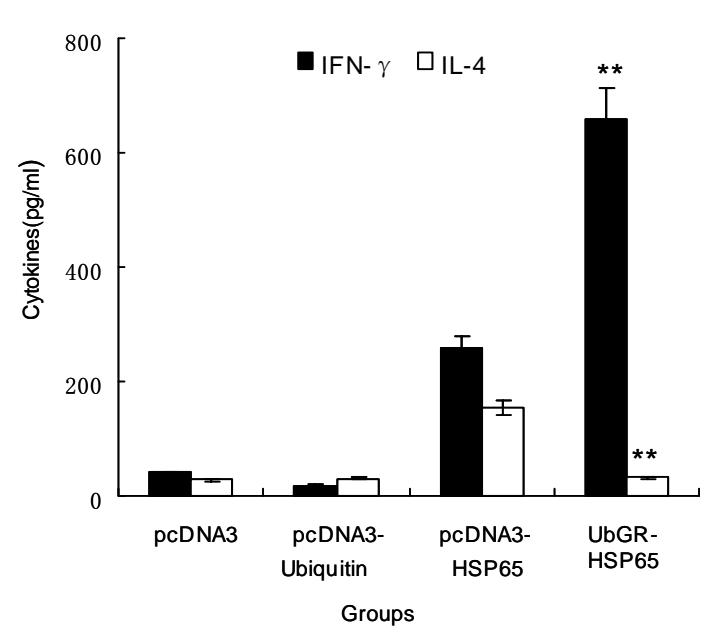

Figure 5. Production of IFN- $\gamma$ and IL-4 from splenocytes of different groups. Different group of mice $(n=8)$ were immunized by the blank vector, pcDNA3-ubiquitin, pcDNA3-HSP65 DNA vaccine or UbGR-HSP65 DNA vaccine at 3 weeks interval. Three weeks after the last immunization, spleen cells from sacrificed mice were pooled and stimulated with $5 \mu \mathrm{g} / \mathrm{ml}$ HSP65 protein for $72 \mathrm{~h}$. Samples were assayed in triplicate. Values and bars represent the mean of released cytokine concentrations and S.D. ${ }^{* *} P<0.01 \mathrm{Ub}-$ GR-HSP65 group $v s$ pcDNA3-HSP65 group. Eight spleens were pooled and the experiment was repeated three times.

UbGR-HSP65 fusion DNA vaccine induced more antigen-specific $\mathrm{CD} 8^{+} \mathrm{T}$ cells than $\mathrm{CD} 4^{+} \mathrm{T}$ cells. These results indicated that UbGR-HSP65 fusion DNA vaccine activated $\mathrm{CD} 4^{+}$and $\mathrm{CD} 8^{+} \mathrm{T}$ cells, particularly $\mathrm{CD} 8^{+} \mathrm{T}$ cells.

\subsection{Improved CTL Response by UbGR-HSP65 Fusion DNA Vaccine}

Cytotoxic T-cell responses were determined with a LDH release assay, after in vitro restimulation, against the target cell line P815-HSP65, which stably expressed the HSP65 protein. P815 cell was used as a negative control. As shown in Figure 7, DNA immunization with HSP65 DNA vaccine resulted in a strong CTL response, which was significantly above the blank vector or in pcDNA3-Ub immunization $(P<0.01)$. Ub fusion DNA vaccine enhanced the cytotoxic T-cell response, compared with HSP65 DNA inoculation $(P<0.01)$. The blank vector or pcDNA3-Ub immunization did not induce CTL response. The spontaneous release was below $10 \%$.

\section{Discussion}

DNA vaccine is one of the most innovative vaccines, which has been reported that DNA vaccines preferentially induced $\mathrm{Th}_{1}$-dominant immune response. The exact mechanism of driving $\mathrm{Th}_{1}$ or $\mathrm{Th}_{2}$ type response has not been well known, but it has been suggested that $\mathrm{CpG}$ motifs from a bacterial plasmid might be responsible for

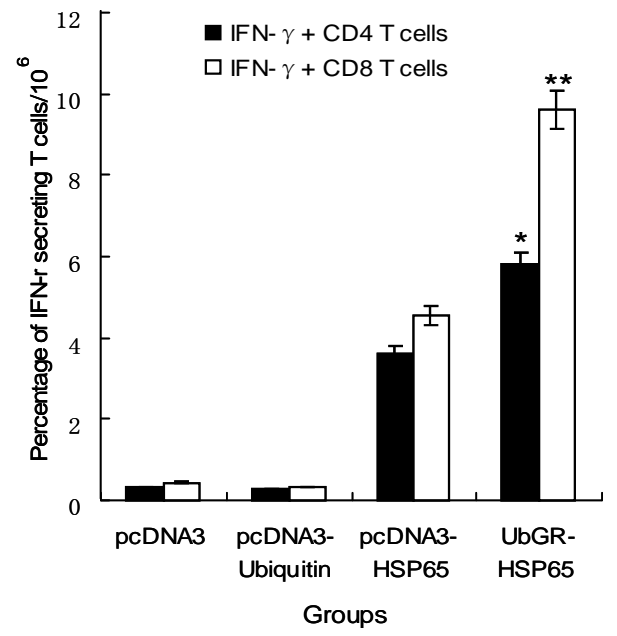

Figure 6. Flow cytometry analysis of HSP65-specific IFN- $\gamma^{+}$ CD4 or $\mathrm{CD8}^{+} \mathrm{T}$ cells. Mice were inoculated as above $(n=8)$. Three weeks after the last immunization, spleen cells from sacrificed mice were pooled and stimulated with $5 \mu \mathrm{g} / \mathrm{ml}$ HSP65 protein for $72 \mathrm{~h}$. The frequency of IFN- $\boldsymbol{y}^{+}$CD4 or CD8 $T$ cells was detected by Flow cytometry. Samples were assayed in triplicate. Values and bars represent the mean of frequency and S.D. ${ }^{* *} P<0.01$ UbGR-HSP65 group $v s$ pcDNA3-HSP65 group; ${ }^{*} P<0.05$ UbGR-HSP65 group $v s$ pcDNA3-HSP65 group. Eight spleens were pooled and the experiment was repeated three times.

driving immune responses toward $\mathrm{Th}_{1}$-type. Th $\mathrm{T}_{1}$-type response has been reported to correlate with protective immunity in certain tumor, bacterial or viral infection, as well as some parasitic disease. Protective immunity against tuberculosis mainly depends on cellular immune responses and some cytokines of $\mathrm{Th}_{1}$-type, such as IFN- $\gamma$. Several DNA vaccines have shown protection against subsequent challenge with M. tuberculosis by establishing a cellular immune response in animals [24]. However, there is still no one DNA vaccine whose immune response could be superior to that of conventional BCG. Hence, in order to improve the DNA vaccines against Mycobacterium tuberculosis, some strategies must be explored to enhance the protective immune response. In our study, we chose Ub to modulate the immune response elicited by HSP65 DNA vaccine.

It is well known that Ub-proteasome pathway is the main source for intracellular protein turnover. MHC lass I most often presents peptides derived from endogenously synthesized proteins, which are degraded by the proteasome. Hence, higher rates of intracellular antigen turnover should increase the number and variety of fragments and peptides available for MHC I binding, which may result in an increase of cell-mediated response to the expressed antigens. To this point, conjugation of the antigen with $\mathrm{Ub}$ should target the endogenously synthesized antigens to the proteasome pathway 


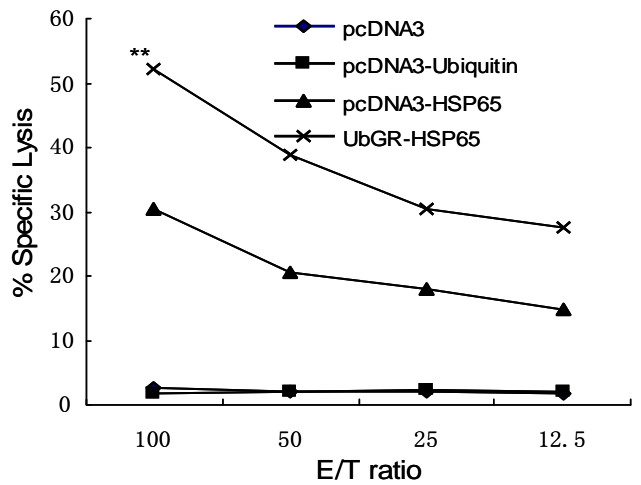

Figure 7. Induction of $\mathrm{CD8}^{+} \mathrm{CTL}$ following immunization with different vaccines. Mice were inoculated as above. The percentage of specific lysis was measured after in vitro restimulation of the in vivo-primed cells with mitomycintreated P815-HSP65 cells. Effector cells [E] were incubated with P815-HSP65 target cells [T] in a LDH release assay. Samples were assayed in triplicate. Results are representative of three independent experiments. ${ }^{* *} P<0.01$ UbGRHSP65 group vs pcDNA3-HSP65 group. Eight spleens were pooled and the experiment was repeated three times

and result in an enhanced cellular immune response. Some researchers have optimized the efficacy of DNA vaccines by increasing the antigen degradation [25-29]. There are two methods of fusing the Ub with the interest protein. One is to mutate the C-terminal residue of $\mathrm{Ub}$ from glycine $(\mathrm{G})$ to alanine (A), resulting in a stable Ub-protein (UbAAg). This stable Ub-protein can be polyubiquitinated and degraded quickly by the proteasome. The other method is to add an arginine (R) to the C-terminus of $\mathrm{Ub}$, resulting in an unstable Ub-protein (UbGR$\mathrm{Ag}$ ). This fusion protein can be quickly recognized and degraded by the Ub system according to the N-rule, also resulting in promoted protein degradation. So, it is essential for a DNA vaccine to induce antigenspecific $\mathrm{CD} 8^{+} \mathrm{T}$ cells based on the $\mathrm{Ub}$ fusion degradation pathway.

Based on the Ub paradigm, we fused UbGR with HSP65 antigen from M.TB in our study. The change of the immune response elicited by UbGR-HSP65 fusion DNA vaccine indirectly showed the change of HSP65 degradation. Compared with the HSP65 DNA immunization, UbGR-HSP65 fusion DNA vaccine resulted in an lower antibody $\mathrm{IgG}$, an enhanced lymphocytes proliferation, a stronger $\mathrm{Th}_{1}$ type immune response and an enhance cytotoxicity of CTL. In order to generate a protective immune response against infection by M.TB, CD4 ${ }^{+}$ but also $\mathrm{CD} 8^{+} \mathrm{T}$-cell responses are essential. In the frequency of IFN- $\gamma$ detection, the frequency of IFN- $\gamma$ level in UbGR-HSP65 was higher than that in HSP65 DNA vaccine group. The increased level of IFN- $\gamma$ resulted from both the $\mathrm{CD} 4^{+} \mathrm{T}$ and the $\mathrm{CD} 8^{+} \mathrm{T}$ cell, particularly from $\mathrm{CD} 8^{+} \mathrm{T}$ cell. Interestingly, the ubiquitination strategy designed to improve MHC I -mediated cellular re- sponses also resulted in improved cytokines and proliferative responses mediated by $\mathrm{CD} 4^{+} \mathrm{T}$ cells. It could be that the increasing protein degradation by the proteasome also yields peptides that could be taken up by MHC II molecules. That modulation of immune response in our experiment is helpful for the protective immunity of Mycobacterium tuberculosis. The modulated immune response indicated that the expressed HSP65 protein had a higher rate of intracellular degradation in a proteasome pathway because of the addition of UbGR. Our result is consistent with the Sharma A's report [28], which showed that immunization with DNA vaccine encoding ORFF fused to $\mathrm{Ub}$ induced higher IFN- $\gamma$, stronger $\mathrm{Th}_{1}$ responses than those of unmodified vaccines. However, no effect was seen for another antigen PyCSP using the same targeting strategies. Rodriguez et al. [30] showed that the fusion of a ubiquitin monomer to the nucleoprotein of lymphocytic choriomeningitis virus led to more rapid and complete degradation, which enhanced cytotoxic T-lymphocyte induction and abrogated antibody induction. However, in Vadlin's study [31], when Ub fused with hepatitis $\mathrm{C}$ virus (HCV) core antigen, an undetectable antibody response and no increase in CTL activity were observed compared with the non-fusion vaccine. In our study, the humoral immune responses were not completely abrogated. Those different results may correlate with the different antigenicity of protein and the different dependence of antigen on Ub.

In conclusion, the data presented above suggested that the fusion of UbGR to DNA vaccine significantly increased the antigen-specific cellular immune response. Infection with $M$. tuberculosis remains largely confined to an intracellular localization. Thereby, it is greatly accepted that protective immune response against $M$. $t u$ berculosis infection involved a cell-mediated response rather than humoral response on the part of the host defences, involving both $\mathrm{CD}^{+}$and $\mathrm{CD} 8^{+} \mathrm{T}$ cells and the ability to respond with $\mathrm{Th}_{1}$-type cytokines, particularly IFN $-\gamma$. Taken together, our results demonstrated that the fusion of UbGR to HSP65 DNA vaccine could be as a new strategy to improve the efficacy of TB DNA vaccines.

\section{Acknowledgments}

We thank Dr. Xiao An for providing us the sera from patients infected with Mycobacterium tuberculosis. This research was supported by the National Natural Science Funds (number 31070121).

\section{REFERENCES}

[1] A. D. Harries and C. Dye, "Tuberculosis," Annals of Tropical Medicine and Parasitology, Vol. 100, No. 5, 
2006, pp. 415-431. doi:10.1179/136485906X91477

[2] A. Zumla, P. Malon, J. Henderson and J. Grange, "Impact of HIV on Tuberculosis," Postgraduate Medical Journal, Vol. 76, No. 895, 2000, pp. 256-268. doi:10.1136/pmj.76.895.259

[3] P. Andersen and T. M. Doherty, "The Success and Failure of BCG-Implications for a Novel Tuberculosis Vaccine," Nature Reviews, Vol. 3, No. 8, 2005, pp. 656-662.

[4] N. R. Gandhi, A. Moll, A. W. Sturm, et al., "Extensively Drug-Resistant Tuberculosis as a Cause of Death in Patients Coinfected with Tuberculosis and HIV in a Rural Area of South Africa," Lancet, Vol. 368, No. 9547, 2006, pp. 1575-1580. doi:10.1016/S0140-6736(06)69573-1

[5] L. Brandt, M. Elhay, I. Rosenkrands, E. B. Lindblad and P. Andersen, "ESAT-6 Subunit Vaccination against $M y$ cobacterium tuberculosis," Infection and Immunity, Vol. 68, No. 2, 2000, pp. 791-795. doi:10.1128/IAI.68.2.791-795.2000

[6] D. Cendron, S. Ingoure, A. Martino, et al., "A Tuberculosis Vaccine Based on Phosphoantigens and Fusion Proteins Induces Distinct Gammadelta and Alphabeta T cell Responses in Primates," European Journal of Immunology, Vol. 37, No. 2, 2007, pp. 549-565. doi:10.1002/eji.200636343

[7] K. Huygen, "DNA Vaccines against Mycobacterial Diseases," Future Microbiology, Vol. 1, No. 1, 2006, pp. 6373. doi:10.2217/17460913.1.1.63

[8] Q. M. Wang, S. H. Sun, Z. L. Hu, F. J. Zhou, M. Yin, C. J. Xiao and J. C. Zhang, "Epitope DNA Vaccines against Tuberculosis: Spacers and Ubiquitin Modulates Cellular Immune Responses Elicited by Epitope DNA Vaccine," Scandinavian Journal of Immunology, Vol. 60, No. 3, 2004, pp. 219-225. doi:10.1111/j.0300-9475.2004.01442.x

[9] O. Lamrabet and M. Drancourt, "Genetic Engineering of Mycobacterium tuberculosis: A Review," Tuberculosis, Vol. 92, No. 5, 2012, pp. 365-376. doi:10.1016/j.tube.2012.06.002

[10] Q. M. Wang, S. H. Sun, Z. L. Hu, M. Ying, C. J. Xiao and J. C. Zhang, "Improved Immunogenecity of a Tuberculosis DNA Vaccine Encoding ESAT6 by DNA Priming and Protein Boosting," Vaccine, Vol. 22, No. 27-28, 2004, pp. 3622-3627. doi:10.1016/j.vaccine.2004.03.029

[11] M. Okada, "Novel Vaccines against M. tuberculosis," Kekkaku, Vol. 81, No. 12, 2006, pp. 745-751.

[12] C. Palma, E. Iona, F. Giannoni, et al., "The Ag85B Protein of Mycobacterium tuberculosis May Turn a Protective Immune Response Induced by Ag85B-DNA Vaccine into a Potent but Non-Protective $\mathrm{Th}_{1}$ Immune Response in Mice," Cellular Microbiology, Vol. 9, No. 6, 2007, pp. 1455-1465. doi:10.1111/j.1462-5822.2007.00884.X

[13] X. Zhang, M. Divangahi, P. Ngai, et al., "Intramuscular Immunization with a Monogenic Plasmid DNA Tuberculosis Vaccine: Enhanced Immunogenicity by Electroporation and Co-Expression of GM-CSF Transgene," Vaccine, Vol. 25, No. 7, 2007, pp. 1342-1352. doi:10.1016/j.vaccine.2006.09.089
[14] D. Wang, J. Xu, Y. Feng, Y. Liu, S. S. Mchenga, F. Shan, J. Sasaki and C. Lu, "Liposomal Oral DNA Vaccine (Mycobacterium DNA) Elicits Immune Response," Vaccine, Vol. 28, No. 18, 2010, pp. 134-142. doi:10.1016/j.vaccine. 2010.02 .058

[15] X. Fan, Q. Gao and R. Fu, "Differential Immunogenicity and Protective Efficacy of DNA Vaccines Expressing Proteins of Mycobacterium tuberculosis in a Mouse Model," Microbiological Research, Vol. 164, No. 4, 2009, pp. 374-382. doi:10.1016/j.micres.2007.04.006

[16] H. J. Ko, S. Y. Ko, Y. J. Kim, E. G. Lee, S. N. Cho and C. Y. Kang, "Optimization of Codon Usage Enhances the Immunogenicity of a DNA Vaccine Encoding Mycobacterial Antigen Ag85B," Infection and Immunity, Vol. 73, No. 9, 2006, pp. 5666-5674.

[17] K. M. Lima, S. A. Santos, V. M. Lima, A. A. CoelhoCastelo, J. M. Rodrigues Jr. and C. L. Silva, "Single Dose of a Vaccine Based on DNA Encoding Mycobacterial HSP65 Protein Plus TDM-Loaded PLGA Microspheres Protects Mice against a Virulent Strain of Mycobacterium tuberculosis," Gene Therapy, Vol. 10, No. 8, 2003, pp. 675-685. doi:10.1038/sj.gt.3301908

[18] K. M. Lima, S. A. dos Santos, R. R. Santos, I. T. Brandao, J. M. Rodrigues Jr. and C. L. Silva, "Efficacy of DNA HSP65 Vaccination for Tuberculosis Varies with Method of DNA Introduction in Vivo," Vaccine, Vol. 22, No. 1, 2003, pp. 49-56. doi:10.1016/S0264-410X(03)00543-7

[19] A. Varshavsky, "The N-End Rule: Functions, Mysteries, Uses," Proceedings of the National Academy of Sciences of the United States of America, Vol. 93, No. 22, 1996, pp. 12142-12149. doi:10.1073/pnas.93.22.12142

[20] M. Cotten, A. Baker, M. Saltik, E. Wagner and M. Buschle, "Lipopolysaccharide is a Frequent Contaminant of Plasmid DNA Preparations and Can Be Toxic to Primary Human Cells in the Presence of Adenovirus," Gene Therapy, Vol. 1, No. 4, 1994, pp. 239-246.

[21] I. Danko, J. D. Fritz, S. Jiao, K. Hogan, J. S. Latendresse and J. A. Wolff, "Pharmacological Enhancement of in vivo Foreign Gene Expression in Muscle," Gene Therapy, Vol. 1, No. 2, 1994, pp. 114-121.

[22] Q. M. Wang, Z. L. Hu, C. J. Xiao, J. C. Zhang and S. H. Sun, "The Expression and Purification of HSP65 Antigen form Mycobacterium tuberculosis in Ecoli," China Biotechnology, Academic Journal of Second Military Medical University, Vol. 24, No. 4, 2004, pp. 74-76.

[23] Q. M. Wang, S. H. Sun, Z. L. Hu, D. Wu and Z. C. Wang, "Immune Response and Protection Elicited by DNA Immunisation against Taenia cysticercosis," Vaccine, Vol. 21 , No. 15,2003 , pp. $1672-1680$. doi:10.1016/S0264-410X(02)00661-8

[24] S. N. Hanif, R. Al-Attiyah and A. S. Mustafa, "Cellular Immune Response in Mice induced by M. tuberculosis PE35-DNA Vaccine Construct," Scandinavian Journal of Immunology, Vol. 74, No. 6, 2011, pp. 554-560. doi:10.1111/j.1365-3083.2011.02604.x

[25] J. L. Brandsma, M. Shlyankevich, D. Zelterman and Y. $\mathrm{Su}$, "Therapeutic Vaccination of Rabbits with a Ubiquitin-Fused Papillomavirus E1, E2, E6 and E7 DNA Vac- 
cine," Vaccine, Vol. 25, No. 33, 2007, pp. 6158-6163. doi:10.1016/j.vaccine.2007.06.012

[26] C. Dobano, W. O. Rogers, K. Gowda and D. L. Doolan, "Targeting Antigen to MHC Class I and Class II Antigen Presentation Pathways for Malaria DNA Vaccines," Immunology Letters, Vol. 111, No. 2, 2007, pp. 92-102. doi:10.1016/j.imlet.2007.05.007

[27] J. H. Chen, Y. S. Yu, H. H. Liu, et al., "Ubiquitin Conjugation of Hepatitis B Virus Core Antigen DNA Vaccine Leads to Enhanced Cell-Mediated Immune Response in BALB/c Mice," Hepatitis Monthly, Vol. 11, No. 8, 2011, pp. 620-628. doi:10.5812/kowsar.1735143X.1372

[28] A. Sharma and R. Madhubala, "Ubiquitin Conjugation of Open Reading Frame F DNA Vaccine Leads to Enhanced Cell-Mediated Immune Response and Induces Protection against Both Antimony-Susceptible and -Resistant Strains of Leishmania donovani," Journal of Immunology, Vol. 183, No. 12, 2009, pp. 7719-7731. doi:10.4049/jimmunol.0900132

[29] L. Ramakrishna, K. K. Anand, M. Mahalingam, K. M. Mohankumar, S. Ramani, N. B. Siddappa, et al., "Codon Optimization and Ubiquitin Conjugation of Human Immunodeficiency Virus-1 Tat Lead to Enhanced Cell-Mediated Immune Responses," Vaccine, Vol. 22, No. 20, 2004, pp. 2586-2598.

[30] F. Rodriguez, J. Zhang and J. L. Whitton, "DNA Immunization: Ubiquitination of a Viral Protein Enhances Cytotoxic T-Lymphocyte Induction and Antiviral Protection but Abrogates Antibody Induction," Journal of Virology, Vol. 71, No. 11, 1997, pp. 8497-8503.

[31] O. Vidalin, E. Tanaka, U. Spengler, C. Trepo and G. Inchauspe, "Targeting of Hepatitis C Virus Core Protein for MHC I or MHC II Presentation Does not Enhance Induction of Immune Responses to DNA Vaccination," DNA and Cell Biology, Vol. 18, No. 8, 1999, pp. 611-621. doi:10.1089/104454999315024 